\title{
Effect of Titanium on the allotriomorphic ferrite transformation kinetics in Medium Carbon-Manganese Steels
}

\author{
C. GARCÍA DE ANDRÉS ${ }^{\mathrm{a}}$, C. CAPDEVILA ${ }^{\mathrm{a}, \mathrm{b}}$, D. SAN MARTÍN ${ }^{\mathrm{a}}$ and F. G. CABALLERO ${ }^{\mathrm{a}}$ \\ ${ }^{a}$ Department of Physical Metallurgy, Centro Nacional de Investigaciones Metalúrgicas \\ (CENIM) Consejo Superior de Investigaciones Científicas (CSIC), Avda. Gregorio del Amo, 8. \\ 28040 Madrid, Spain \\ ${ }^{b}$ Department of Materials Science and Metallurgy, University of Cambridge, Pembroke Street, \\ Cambridge CB2 3QZ, UK
}

\begin{abstract}
The influence of microalloying elements on nucleation and growth kinetics of allotriomorphic ferrite has been investigated by means of dilatometric and microstructural analysis in five medium carbon-manganese steels $(0.3 \mathrm{wt}-\% \mathrm{C}-1.4 \mathrm{wt} \% \mathrm{Mn})$. A careful comparison of the nucleation and growth kinetics curves of a C-Mn steel and microalloyed steels containing $\mathrm{V}$, $\mathrm{Ti}$ and Mo subjected to isothermal transformation, showed that $\mathrm{V}$ and Mo delay the allotriomorphic ferrite transformation whereas Ti speeds it up.
\end{abstract}

Keywords: Microalloyed steels, Allotriomorphic Ferrite, Nucleation, Growth Kinetics. 


\section{Introduction}

Recent works have demonstrated that medium carbon microalloyed forging steels with acicular ferrite microstructure can be manufactured at industrial scale [1-5]. The main interest of this microstructure lies in the good combination of mechanical properties that presents as compared with bainite and especially with ferritic-pearlitic microstructures. In those steels, acicular ferrite is always formed after the growth of allotriomorphic ferrite and pearlite. As a consequence, acicular ferrite transformation is inevitably influenced by previous allotriomorphic ferrite formation. The role of the allotriomorphic ferrite to promote the formation of acicular ferrite to the detriment of bainite has been reported in previous works [6-9]. The results of these investigations allow concluding that the amount of acicular ferrite increases as allotriomorphic ferrite is present along the austenite grain boundaries. Therefore, with the aim of understanding the decomposition of austenite into allotriomorphic ferrite, the total amount of acicular ferrite present in the microstructure should be controlled. Although several investigations have been reported in the literature [10-13] about the decomposition kinetics of austenite into allotriomorphic ferrite in medium carbon microalloyed steels, there is a lack of information about the role of the microalloying elements on this phase transformation.

The purpose of this investigation is to clarify experimentally the influence of Ti, V, V-Ti and VTi-Mo additions on the nucleation and growth kinetics of austenite-to-allotriomorphic ferrite transformation and, indirectly, on the development of the intragranular formation of acicular ferrite in microalloyed forging steels. 


\section{Materials and experimental procedures}

A conventional carbon manganese steel (C-Mn) and four microalloyed steels with different titanium, vanadium and molybdenum contents have been considered for this investigation. Their chemical compositions are shown in Table 1.

Table 1. Chemical compositions (mass \%).

\begin{tabular}{cccccccccccc}
\hline Steel & $\mathrm{C}$ & $\mathrm{Mn}$ & $\mathrm{Cu}$ & $\mathrm{Cr}$ & $\mathrm{S}$ & $\mathrm{Si}$ & $\mathrm{Al}$ & $\mathrm{Ni}$ & $\mathrm{V}$ & $\mathrm{Ti}$ & $\mathrm{Mo}$ \\
\hline $\mathrm{C}-\mathrm{Mn}$ & 0.31 & 1.22 & - & 0.138 & 0.011 & 0.25 & - & 0.10 & 0.004 & - & 0.03 \\
$\mathrm{~V}$ & 0.33 & 1.49 & 0.27 & 0.08 & 0.002 & 0.25 & 0.027 & 0.11 & 0.240 & 0.002 & 0.04 \\
$\mathrm{Ti}$ & 0.36 & 1.56 & 0.10 & 0.24 & 0.008 & 0.33 & 0.029 & 0.05 & 0.004 & 0.026 & 0.02 \\
$\mathrm{~V}-\mathrm{Ti}$ & 0.32 & 1.39 & 0.13 & 0.13 & 0.021 & 0.33 & 0.049 & 0.14 & 0.129 & 0.039 & 0.03 \\
$\mathrm{~V}-\mathrm{Ti}-\mathrm{Mo}$ & 0.30 & 1.51 & 0.20 & 0.25 & 0.030 & 0.32 & 0.020 & 0.14 & 0.110 & 0.020 & 0.12 \\
\hline
\end{tabular}

The isothermal decomposition of austenite into allotriomorphic ferrite has been analyzed by means of an Adamel Lhomargy DT1000 high-resolution dilatometer described elsewhere [14]. The dimensional variations of the cylindrical specimen ( $2 \mathrm{~mm}$ in diameter and $12 \mathrm{~mm}$ in length) are transmitted via an amorphous silica pushrod. These variations are measured by a linear variable differential transformer (LVDT) sensor in a gas-tight enclosure enabling to test under vacuum or in an inert atmosphere. The DT1000 dilatometer is equipped with a very low thermal inertia radiation furnace. The power radiated by two tungsten filament lamps is focussed on the specimen by means of a bi-elliptical reflector. The temperature is measured with a 0.1-mm diameter Chromel-Alumel (Type K) thermocouple welded to the specimen. Cooling is carried out by blowing a jet of helium gas directly onto the specimen surface. The helium flow-rate during cooling is controlled by a proportional servovalve. These devices ensure an excellent efficiency 
in controlling the temperature and holding time of isothermal treatments and also ensure fast cooling $\left(200 \mathrm{Ks}^{-1}\right)$ in quenching processes.

Table 2. Austenitization conditions.

\begin{tabular}{cccc}
\hline Steel & Temperature, $\mathrm{K}$ & Time, $\mathrm{s}$ & PAGS, $\mu \mathrm{m}$ \\
\hline C-Mn & 1473 & 120 & 70 \\
$\mathrm{~V}$ & 1473 & 300 & 75 \\
$\mathrm{Ti}$ & 1523 & 360 & 65 \\
$\mathrm{~V}-\mathrm{Ti}$ & 1523 & 180 & 72 \\
V-Ti-Mo & 1473 & 120 & 75 \\
\hline
\end{tabular}

Dilatometric samples were austenitized in vacuum $(1 \mathrm{~Pa})$ at a constant rate of $5{ }^{\circ} \mathrm{C} / \mathrm{s}$. Since the prior austenite grain size (PAGS) exerts an important influence on the growth kinetics of allotriomorphic ferrite [15-19], austenitization conditions were selected to obtain similar PAGS in all the steels (Table 2). A coarse PAGS of $70 \mu \mathrm{m}$ approximately was selected to achieve a slow growth rate of the allotriomorphs and thus facilitate the investigation of the growth kinetics of allotriomorphic ferrite. After austenitization, specimens were isothermally transformed at temperatures ranging from 973 to $873 \mathrm{~K}$ at different holding times and subsequently quenched to room temperature. Specimens were grounded and polished using standardized metallographic techniques. 2 pct-Nital etching solution was used to reveal the ferrite microstructure by optical microscopy. The volume fraction of allotriomorphic ferrite ( $V A A F)$ was estimated from optical micrographs by an unbiased systematic manual point counting procedure based on stereological principles [20].

The nucleation time for allotriomorphic ferrite can be defined as the minimum time at which it is possible to detect a few allotriomorphs $(v f A F<1 \%)$ nucleated on the austenite grain boundaries. 
This parameter has been measured by dilatometry and optical metallography. A detailed analysis of the dilatometric curve associated to the isothermal decomposition of austenite (relative change in length $(d L / L o$ ) versus time $(t))$ (Fig. 1$)$ allows determining an interval of time, $\Delta t$, in which it is more likely to find the nucleation time. Subsequent isothermal heat treatments were carried out at different holding times within the $\Delta t$ interval. Finally, an accurate metallographic analysis determined the nucleation time.

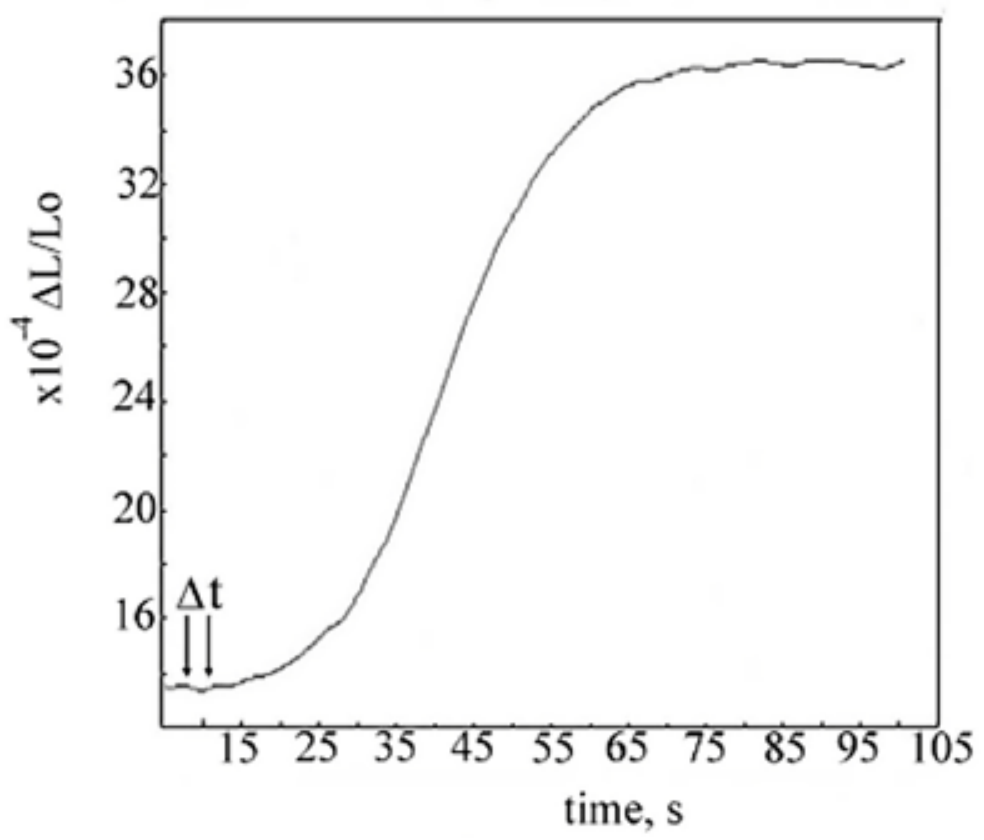

Fig. 1. Dilatometric curve obtained during isothermal decomposition of austenite into allotriomorphic ferrite. 


\section{Results and discussion}
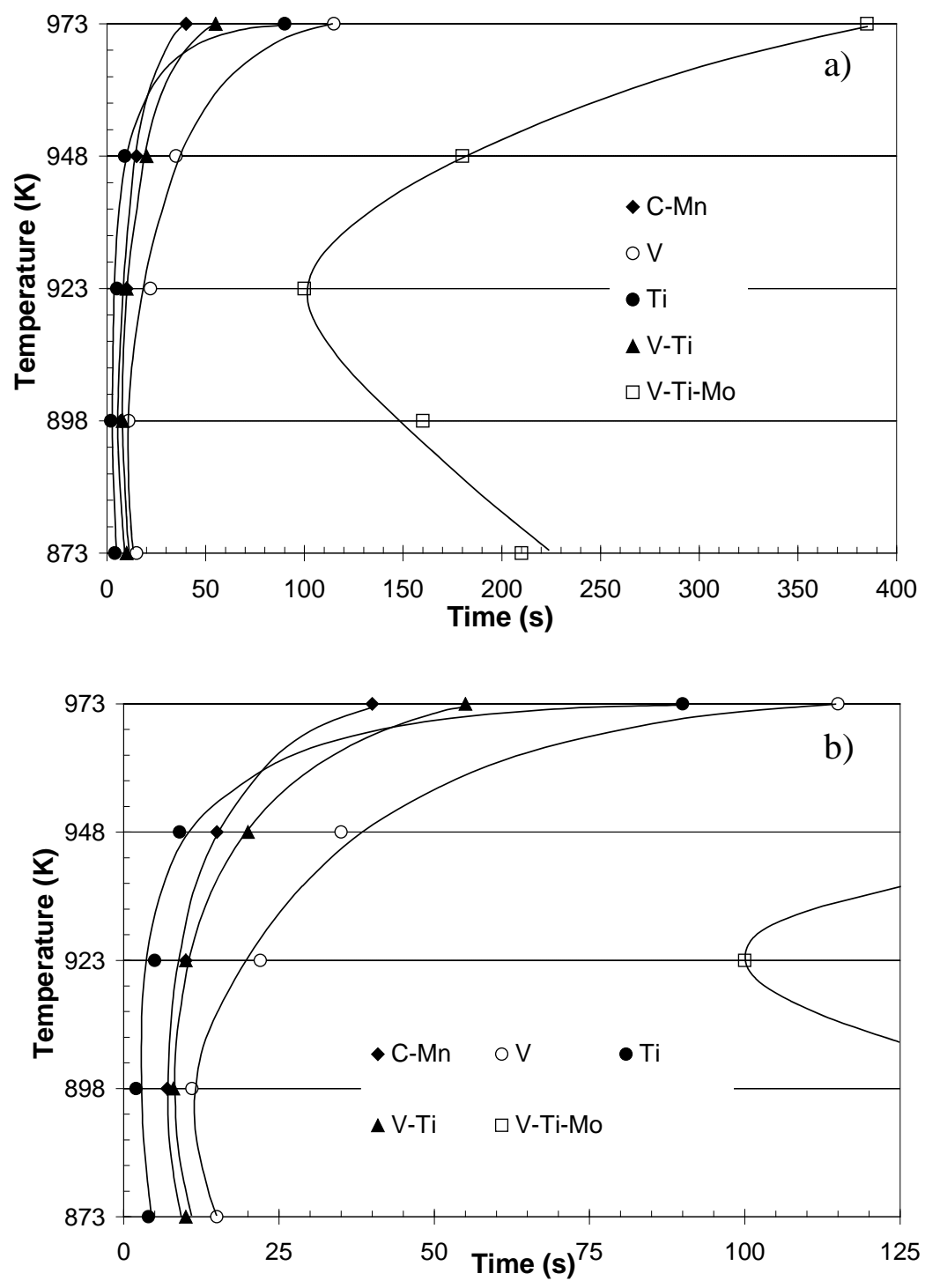

Fig. 2. Nucleation of allotriomorphic ferrite. (a) Wide time scale (b) short time scale.

Figure 2 shows the allotriomorphic ferrite nucleation curves for the five steels. Figure $2 b$ illustrates those curves for a shorter time scale. Comparison of the nucleation curves of V, Ti and C-Mn steels shows that vanadium delays the nucleation of allotriomorphic ferrite, whereas titanium speeds it up. However, according to the nucleation curve of V-Ti steel, it seems that the 
combined addition of $\mathrm{V}(0.13 \mathrm{wt}-\%)$ and $\mathrm{Ti}(0.039 \mathrm{wt}-\%)$ does not change nucleation time significantly as compare with C-Mn steel due to the opposite effect of both microalloying elements. On the other hand, the comparison between the nucleation curves of V-Ti and V-Ti-Mo steels proves that molybdenum strongly retards the nucleation of the allotriomorphic ferrite.

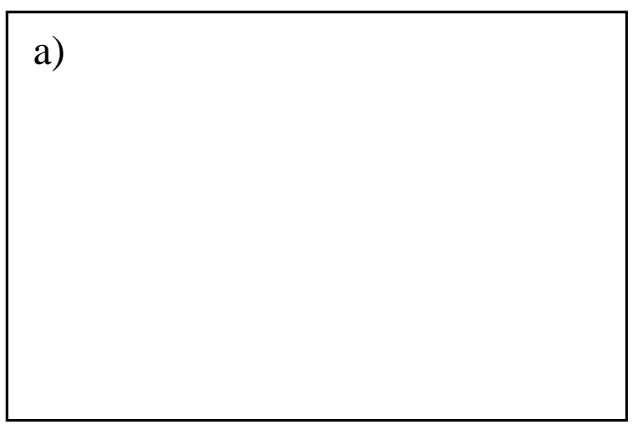

b)

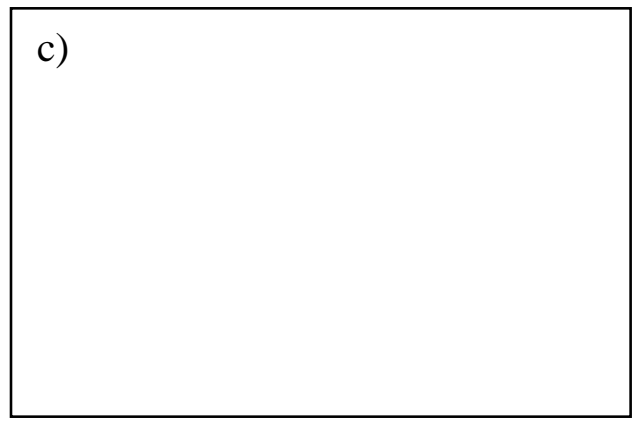

d)

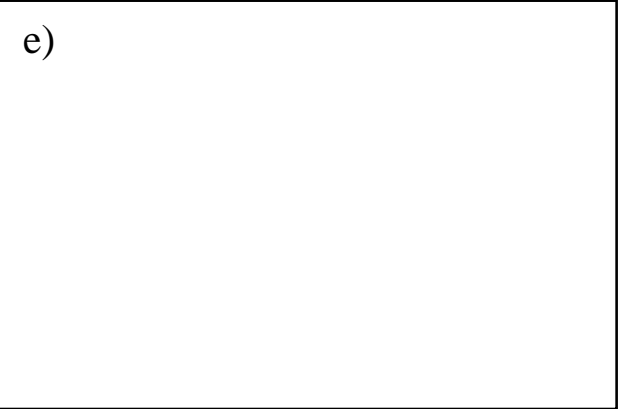

Fig. 3. Optical micrograph of the initial stage of the isothermal formation of allotriomorphic ferrite at $898 \mathrm{~K}$ in: a) C-Mn steel, t $=7 \mathrm{~s}$; b) V steel, t $=11 \mathrm{~s}$; c) Ti steel, t $=2 \mathrm{~s}$; d) V-Ti steel, t = $8 \mathrm{~s}$; and at $923 \mathrm{~K}$ in: e) V-Ti-Mo steel, t $=100 \mathrm{~s}$. 
The temperatures $\left(T_{i}\right)$ at which the nucleation time of allotriomorphic ferrite nucleation $\left(t_{i}\right)$ is minimum (nose of the nucleation curves) are reported in Table 3. $T_{i}$ temperature is approximately the same for C-Mn, V, Ti and V-Ti steels ( $~ 898 \mathrm{~K})$. In this sense, V, Ti and V-Ti additions do not exert any influence on this temperature. However, the molybdenum content in V-Ti-Mo steel raises $T_{i}$ temperature to $923 \mathrm{~K}$, which is consistent with Kinsman and Aaronson's work [21]. Micrographs in Fig. 3 show the initial stage of allotriomorphic ferrite formation in the five steels investigated in this work at their respective $T_{i}$ temperatures.

Table 3. Temperature and time at the nose of nucleation curves

\begin{tabular}{ccc}
\hline Steel & $T_{i}$ Temperature, $\mathrm{K}$ & $t_{i}$ Nucleation Time, $\mathrm{s}$ \\
\hline C-Mn & 898 & 7 \\
$\mathrm{~V}$ & 898 & 11 \\
$\mathrm{Ti}$ & 898 & 2 \\
$\mathrm{~V}-\mathrm{Ti}$ & 898 & 8 \\
V-Ti-Mo & 923 & 100 \\
\hline
\end{tabular}

On the other hand, the effect of microalloying elements on the growth kinetics of allotriomorphic ferrite has been studied. With that purpose, the $T_{i}$ temperatures listed in Table 3 have been selected. Experimental results of the isothermal decomposition kinetics are shown in Fig. 4 for the five steels. In this figure, the nucleation time $\left(t_{i}\right)$ of each steel is taken as origin of time. At these $T_{i}$ temperatures, the total isothermal decomposition of austenite yields to a ferrite-pearlite microstructure in all the studied steels. 


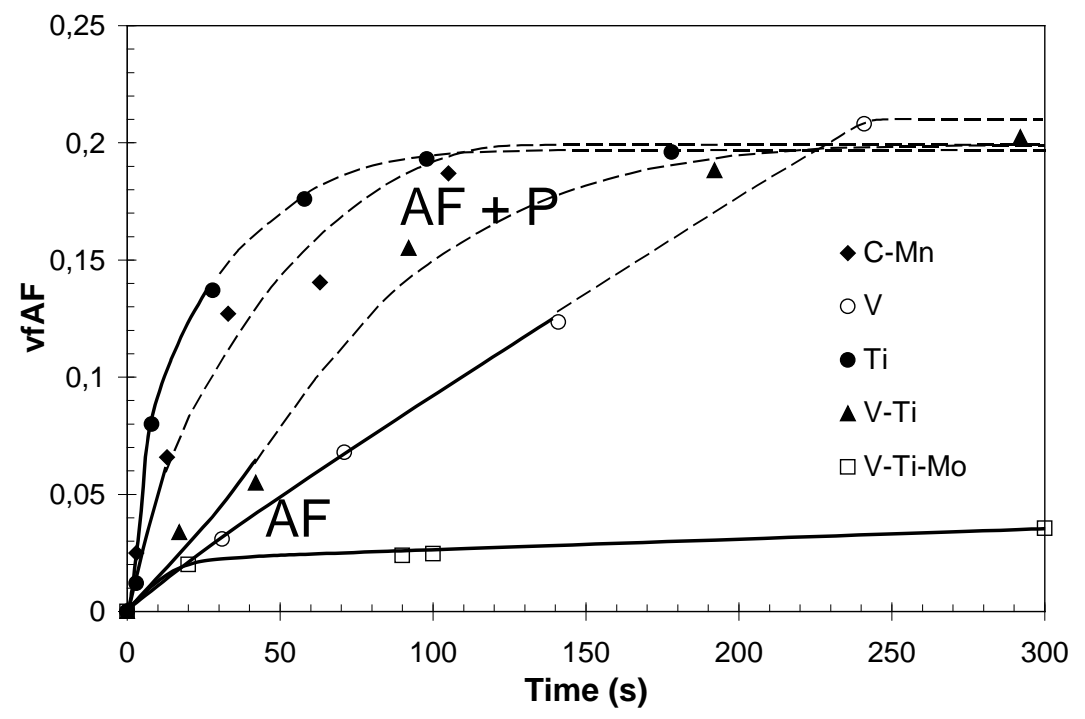

Fig. 4. Isothermal decomposition kinetics at $I_{i}$ temperatures.

Table 4 lists the time required to nucleate pearlite in all these steels, taking as origin the corresponding $t_{i}$ nucleation time of allotriomorphic ferrite.

In Fig. 4 the $v f A F$ formed at times longer than pearlite nucleation (Table 4) is represented by dashed lines.

Table 4. Nucleation time of pearlite.

\begin{tabular}{cc}
\hline Steel & Nucleation Time, s \\
\hline C-Mn & 13 \\
V & 139 \\
Ti & 28 \\
V-Ti & 42 \\
V-Ti-Mo & $>1100$ \\
\hline
\end{tabular}

The influence of the microalloying elements on the growth kinetics of allotriomorphic ferrite is clear from the results shown in Fig. 4. Vanadium decreases the growth rate of allotriomorphic 
ferrite, whereas titanium speeds it up. The combined addition of V (0.13 wt-\%) V and Ti (0.039 wt-\%) causes a slower growth rate as compare with that for C-Mn steel. On the other hand, the growth rate in V-Ti-Mo steel is significantly slower than in the other four steels. Bearing in mind the molybdenum content of steels $(\leq 0.04$ wt-\% Mo in C-Mn, V, Ti, and Ti-V steels; 0.12 wt-\% Mo in V-Ti-Mo steel), there is some evidence to suggest that this element exerts an important influence on the growth kinetics of allotromorphic ferrite. Moreover, molybdenum is responsible for the delay in the formation of pearlite in V-Ti-Mo steel, which is in accordance with other investigations $[22,23]$. The nucleation time of pearlite is found much longer in this steel (Table 4). Vanadium and titanium also seem to have a certain influence on the nucleation of pearlite.

\section{Conclusions}

Vanadium delays the nucleation and growth kinetics of allotriomorphic ferrite in medium carbonmanganese steels ( 0.3 wt-\% C - 1.4 wt-\% Mn), whereas titanium speeds up both of them. The addition of 0.12 wt-\% Mo in a microalloyed steel containing vanadium and titanium significantly delays the nucleation and growth kinetics of allotriomorphic ferrite.

\section{Acknowledgements}

The authors acknowledge financial support from the CICYT-Spain (project PETRI 95-0089-OP). 


\section{References}

[1] I. Madariaga, I. Gutierrez, C. García de Andrés and C. Capdevila, Scripta Metall. Mater. 41 (1999) 229.

[2] I. Madariaga and I. Gutiérrez, Acta Mater. 47 (1999) 951.

[3] I. Madariaga, I. Gutiérrez and J. L. Romero, Metall. Trans. 29A (1998) 1003.

[4] M. A. Linaza, J. L. Romero, J. M. Rodríguez-Ibabe and J.J. Urcola, Scripta Metall. 29 (1993) 1217.

[5] I Madariaga, J. L. Romero and I. Gutiérrez, Metall. Trans. 29A (1998) 1003.

[6] C. García De Andrés, C. Capdevila, and F.G. Caballero, in: M Carsí, F. Peñalba, O.A. Ruano and B.J. Fernández (Eds.), Proceedings of the Congreso Nacional de Tratamientos Térmicos y de Superficie TRATERMAT 98, Madrid, Spain, May 26-29, 1998, p. 135.

[7] H.K.D.H. Bhadeshia, Mater. Sci. Tech. 1 (1985) 497.

[8] S.S. Babu and H.K.D.H. Bhadeshia, and L.E-. Svensson, J. Mater. Sci. Lett. 10 (1991) 142.

[9] S.S. Babu and H.K.D.H. Bhadeshia, Mater. Sci. Tech. 6 (1990) 1005. 
[10] C. Capdevila, F.G. Caballero and C. García de Andrés, Metall. Mater. Trans. A 32A (2001). In press.

[11] C. García de Andrés, C. Capdevila and F.G. Caballero and H.K.D.H. Bhadeshia, Scripta Mater. 39 (1998) 853.

[12] C. Capdevila, C. García de Andrés and F.G. Caballero, Scripta Mater. In press

[13] C. Capdevila, C. García de Andrés and F.G. Caballero, Scripta Mater. In press

[14] C. García de Andrés, G. Caruana and L.F. Álvarez, Mater. Sci. Eng. A241 (1998) 211.

[15] J. Barford and W.S. Owen, JISI 197 (1961) 146.

[16] A.K. Sinha, Ferrous Physical Metallurgy, Butterworths, Boston, 1989, p. 309.

[17] K.C. Russell, Acta Metall. 16 (1968) 761.

[18] K.C. Russell, Acta Metall. 17 (1969) 1123.

[19] H.K.D.H. Bhadeshia, Metal Sci. 16 (1982) 159.

[20] G.F. Vander Voort, Metallography. Principles and Practice, McGraw-Hill Book Company, New York, 1984, p. 426. 
[21] K.R. Kinsman and H.I. Aaronson, Transformations and Hardenability in Steels, Climax Molybdenum Co., Ann Arbor, Michigan, USA, 1967, p. 39.

[22] R.W.K. Honeycombe, Steels, Microstructure and Properties, Metallurgical and Materials Science Series, Edward Arnold Publishers Ltd., London, U.K., 1981, p. 62.

[23] G. Krauss, Steels: Heat Treatment and Processing Principles, ASM International, Materials Park, Ohio, USA, 1989, p. 21. 